\title{
NON-CONVENTIONAL GEOELECTRIC ARRAYS - PRACTICAL RESULTS OF THE OTKA PROJECT K49604
}

\author{
S Szalai ${ }^{1}$, M VArga $^{2}$, A Novák $^{1}$, L Szarka $^{1}$ \\ ${ }^{1}$ Geodetic and Geophysical Research Institute \\ of the Hungarian Academy of Sciences, POB 5, H-9401 Sopron, Hungary, \\ e-mails: szalai@ggki.hu, novak@ggki.hu, szarka@ggki.hu \\ ${ }^{2}$ KBFI-TRIÁSZ Kft. Hungary, Budapest, e-mail: triaszkft@t-online.hu
}

[Manuscript received March 1, 2011; accepted August 22, 2011]

\begin{abstract}
In this paper we provide a comprehensive summary about the practical results of the OTKA project K49604. 1. We calculated the consequences of incorrect positioning of the electrodes for various multielectrode systems. In practice these effects were found to be negligible. The only exception is the case of rocky surface, where it is impossible to put the electrodes in the desired positions. The errors can however be kept within an acceptable range, if the electrodes of the linear arrays are put off-set, at right angles from the measuring line. A five-six times larger off-set has less effect than a certain mis-position along the line, connecting the electrodes. 2. We carried out tensorial geoelectric measurements around the Cistercian Monastery at Pilisszentkereszt. Areal measurements provide much more detailed and unambiguous anomalies than 2D profile measurements, and the tensor invariant representation of apparent resistivity anomalies provides a realistic picture about the lateral variation of the subsurface resistivity, even in field circumstances. 3. We tested the applicability of 3D electrical resistivity tomography (ERT) technique to detect landmines in different soil conditions and at various depths. Metallic and non-metallic landmines buried in wet and dry soils had been synthetically modeled. According to the inverted resistivity data using the dipole axial array in wet environment, it was possible to locate the metallic and non-metallic landmines as long as the noise level was about $5 \%$. 4. We elaborated moreover a geoelectrical procedure which is able to map multidirectional fissure systems by combining geoelectrical profiling and geoelectrical azimuthal measurements. Results received by using both the so-called null-, and traditional arrays were jointly interpreted. The humidity of the fissures affects the measured results significantly, and in a meaningful way. 5. We presented the socalled standardized pricking probe (PP) surveying technique and demonstrated its usefulness in an archaeological study. The PP images proved to be definitely more close to the realistic shape of the buried chapel than the geoelectric and magnetic measurements, and they also revealed more details about the subsurface than the georadar. The optimum PP parameters: horizontal interval, pricking depth, observable quantity and its way of presentation were optimized through field experiments. For more details see the cited publications. The figures ever published in Hungarian journals are not reproduced here.
\end{abstract}

Keywords: 3D ERT; geometric noise; landmine; multidirectional fissure system; null-array; pricking probe survey; tensorial geoelectric measurement 


\section{Studying of errors due to incorrect positioning of electrodes of multielectrode arrays}

As a first step of a systematic noise study we calculated the errors of geometrical origin (i.e. errors, originating from a possible incorrect positioning of electrodes), and the effect of these errors on various multielectrode arrays (Szalai et al. 2007, 2008a).

In realistic field conditions, in spite of the greatest possible care, the electrode positions contain some inaccuracy: either in case of dense undergrowth, or varied topography, or very rocky field. In all these cases, it is not possible to put the electrodes in their theoretical position. As a consequence, the data will contain some error. The extent of such inaccuracies was exactly determined by using a laser distance meter. Then, we computed their effect on the resulting apparentand inverted resistivity data. It can be seen from the inverted pseudosections of the PDP array, taking into account the actual positions of the electrodes and the theoretical values of the geometrical factor, that the positioning errors may lead to pseudo-anomalies of up to 20 pc even in those cases, when the differential distance values $\left|r_{\text {ideal }}-r_{\text {real }}\right|$ are minimized. Ignoring the most inaccurate electrode positions, the inverted results will still contain some pseudo-anomalies. It is a better solution to minimize the $x$ component of the differential distance $\left|x_{\text {ideal }}-x_{\text {real }}\right|$, where $x$ is the profile direction. Namely even an intentional off-position of the electrodes in direction $y$ hardly has any influence on the results.

As we found, the usual positional errors are insignificant. Where the normal positional errors cannot be guaranteed, the aforementioned off-position provides satisfactory results (Fig. 1). Keeping all these things in mind, the reliability of the data will improve, even in case of high surface rockiness.

The aforementioned investigations were carried out for Wenner- $\alpha$, Wenner- $\beta$, pole-dipole and pole-pole arrays. In the light of our investigations, the usual assumption about random noise seems to be an oversimplification: 1 . The consequences of the positioning errors on the pseudosection of apparent- and inverted resistivities depend very much on the array geometry (the increasing order of these effects is: $\mathrm{PP}, \mathrm{W} \alpha, \mathrm{PDP}, \mathrm{W} \beta) ; 2$. the error propagates systematically and not randomly. Consequently in the inverted resistivity images the size of the false anomalies can be large.

It is worth confronting our conclusions and the numerical practice, since in the numerical modelling practice 1 . the random error is assumed be the same, indifferently on the array, 2. to the forward-modeled data always a random error is added.

In the light of our conclusions it would be especially important to investigate in details, if the assumption of numerical modelling about a random error is at all realistic. 


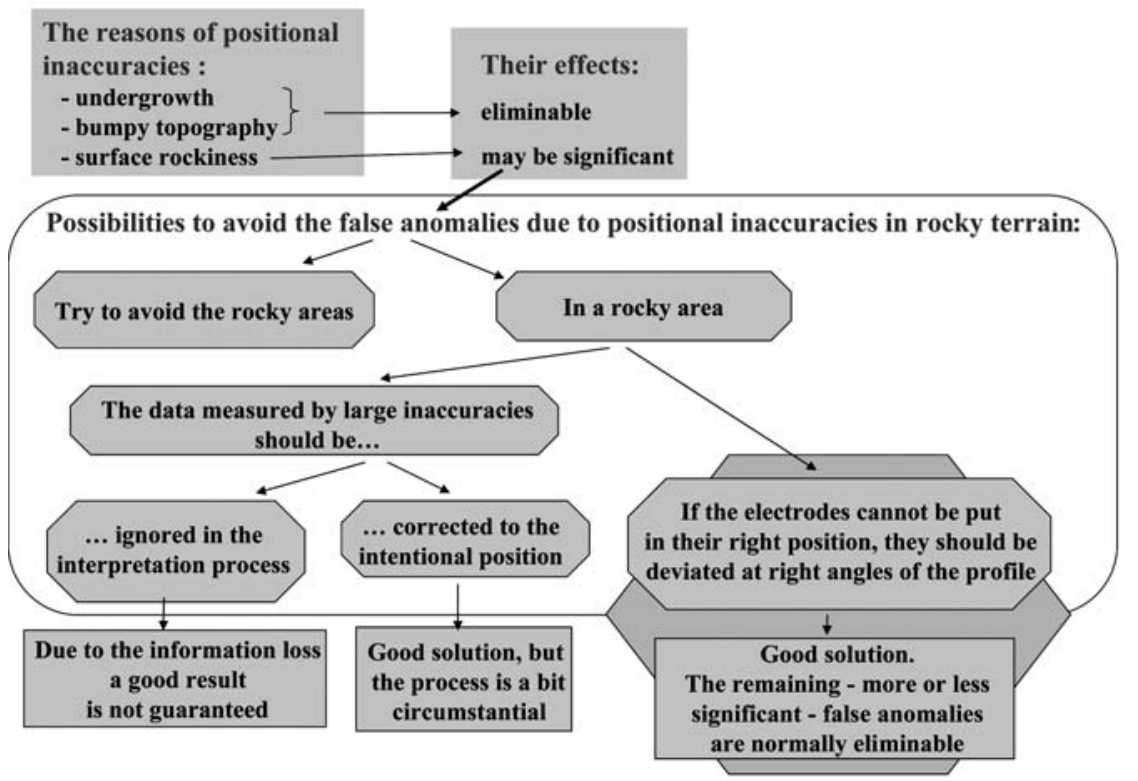

Fig. 1. The possible sources of positional inaccuracies, their effects, and the possibilities how to avoid them

\section{Development of an imaging technique from data of multielectrode potential gradient mapping}

We have elaborated a process for the three-dimensional interpretation of large geoelectric data sets, which proved to be very successful in an archaeological investigation (Novák et al. 2005a, 2005b, Varga et al. 2008). Although this method provides rather qualitative than quantitative results about the spatial distribution of the subsurface, in many cases it is sufficient. It will be illustrated with examples from the Cistercian Monastery at Pilisszentkereszt.

In the applied electrode array the equidistant grid of measuring or potential electrodes is distributed over the investigated area, while the current electrodes are at some distance. The relative electrode potential of each potential electrode is measured for both current electrode directions. Then a tensorial data processing is carried out. We determined various tensorial invariants, which proved to be especially useful (Varga et al. 2008).

Special field studies showed that a change in the direction of current electrodes results only in a change of $1.5-2 \%$ in the tensorial invariants.

According to numerical results, all "one-dimensional" invariants (e.g. $\varrho_{\text {ssq }}, \varrho_{\text {trace }}$, $\varrho_{\text {det }}$ or $\left.\varrho_{I_{1}}\right)$ provide true plan-view images. The "two-dimensional" invariants provide information about the characteristic sides and strike directions, while the "three-dimensional" invariants delineates the corners, i.e. the abrupt change in the strike directions. When controlling all these numerical results in the field, all "onedimensional" invariants proved to be useful, but the "multidimensional" invariants were too noisy (Varga et al. 2008). 

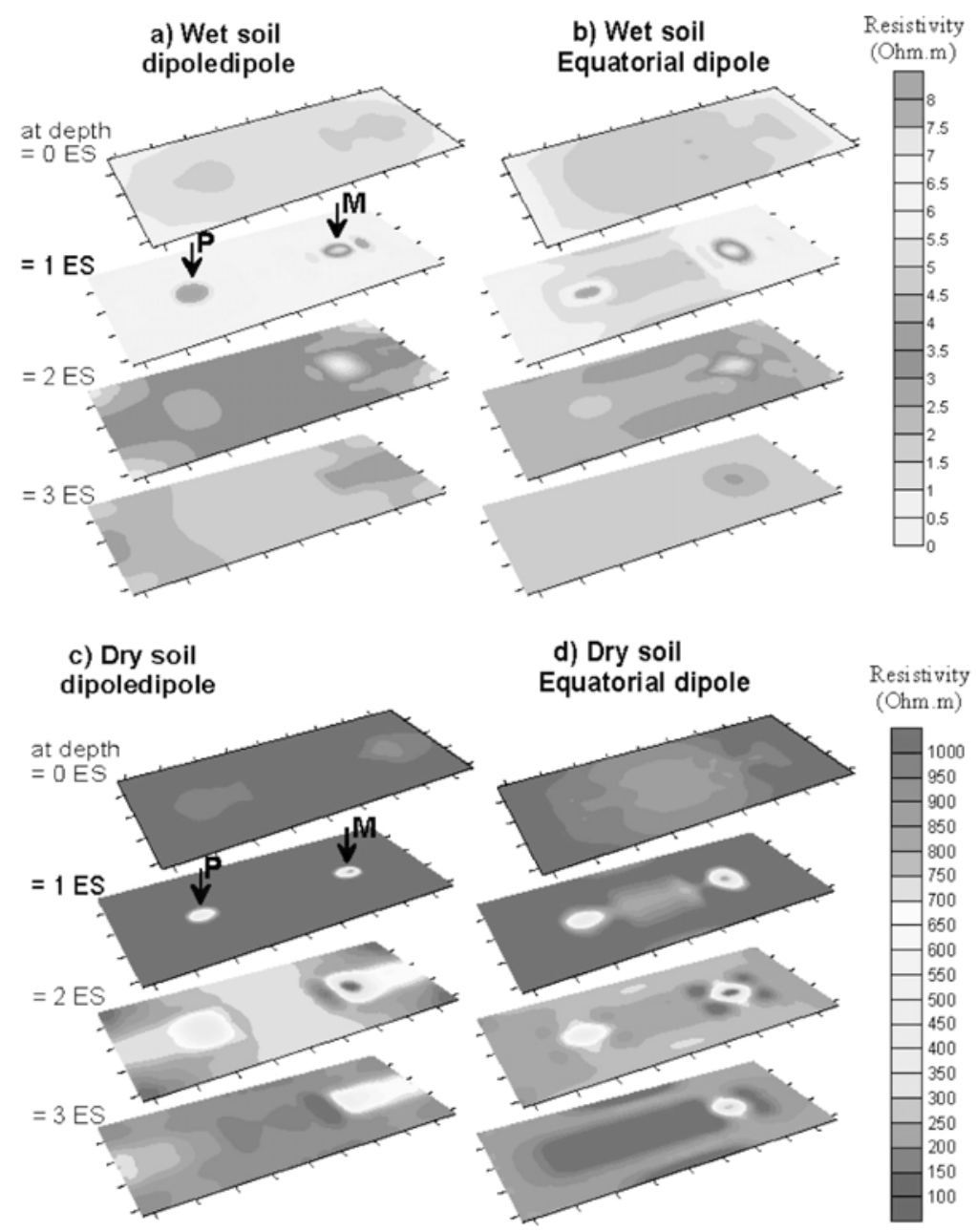

Fig. 2. Inverted models using robust $L_{1}$ norm for buried metallic and non-metallic landmines in wet and dry environments. ES is the electrode separation. $\mathrm{P}$ and $\mathrm{M}$ are the non-metallic (plastic) and metallic landmines, respectively

\section{Detection possibilities of landmines by using 3D geoelectric measurements}

We tested the applicability of electrical resistivity tomography (ERT) technique to detect landmines in different soil conditions and at various depths (Metwaly et al. 2008). Metallic and non-metallic landmines buried in wet and dry soils had been synthetically modeled (Fig. 2, Metwaly et al. 2008). Two electrode configurations (dipole axial and dipole equatorial) that are applicable to use with the towed capacitive electrode system were tested to choice the optimum acquisition parameters. The electrode separations were set to be a function of landmine dimensions, while the buried depths ranged between 1 to 3 times unit electrode separations. 

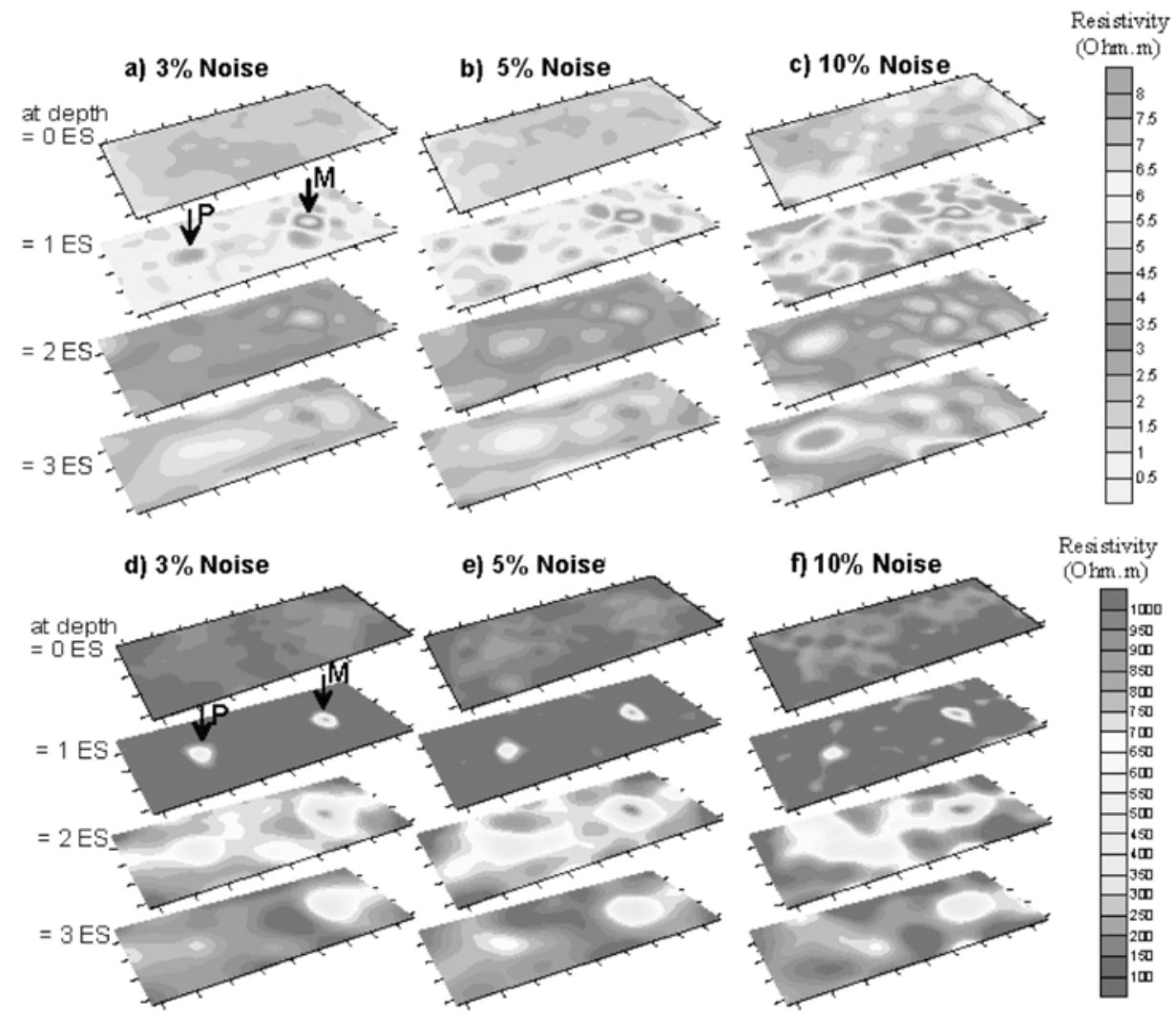

Fig. 3. Inverted models using robust $L_{1}$ norm for buried metallic $(\mathrm{M})$ and non-metallic $(\mathrm{P})$ landmine in wet and dry environments with different percentage of noise

From the numerical simulations that were carried out using the 3D imaging technique, we summarize the success and failures below. The inversion results using the robust $L_{1}$ norm least squares optimization method tended to produce relatively sharp resistivity images of the landmines (Fig. 2). Both applied electrode arrays were able to detect the metallic and even the non-metallic landmines either in wet or dry soils methods with good vertical accuracy.

The inversion of contaminated resistivity data with different noise amplitudes acquired for metallic and non-metallic landmines in different soil conditions and at various depths have been tested, as well (Fig. 3, Metwaly et al. 2008). According to the inverted resistivity data using the dipole axial array in wet environment, it was possible to locate the metallic and non-metallic landmines as long as the noise level was about $5 \%$. The inverted images with high noise levels (10\%) were distorted and neither the metallic nor the non-metallic landmines could be clearly detected. Conversely, in dry soil even if the resistivity data was highly contaminated with $10 \%$ of noise amplitudes, the inversion results clearly showed the location of metallic and non-metallic landmines.

Another test showed the capability of the ERT technique to locate landmines 
buried in different environments at three depths. The depths of the metallic and non-metallic landmines were set to be equal to 1, 2 and 3 unit electrode separations. Both landmine types in the wet and dry soils could be clearly detected. However, with increasing buried depth the inversion results showed quite distorted images. One possible solution for increasing the spatial resolution at this depth was to increase the unit electrode separation relative to the landmine dimension. Similarly, the inversion of noisy data for the same models and parameters showed that the metallic mines at the three depth levels gave significant anomalies in both soil types. However, the non-metallic landmines in wet and dry soils could be detected as long as the depth is not greater than the double the electrode separations and the noise level is lower than $10 \%$. As either the buried depth or the noise level increased, only the shallow non-metallic landmines could be detected in dry soil.

Based on the synthetic experiments, we conclude that: 1. the greatest advantage of the electrical technique (ERT) in the field of landmine is that it works well in wet environment where the other detection techniques like MD (metal detector) and GPR (ground-penetrating radar) are perform poorly. 2. The ERT technique is able to work effectively together with the classical landmine prospecting tools or at least as a confirming tool for the suspicious landmine areas. 3. The horizontal spatial resolution of the resistivity is actually a function of the electrode density and reconstruction depth. Therefore, the landmine targets with dimensions greater than the unit electrode separation and buried at depth equal or less than the unit electrode separation have overestimated spatial resolution.

\section{Investigation of multidirectional fissure systems}

\subsection{Detection of multidirectional fissure systems by using analogue model measurements}

We carried out analogue model measurements in order to develop a geoelectric method to detect fissure directions in case of multiple fissured medium (Szalai et al. 2009a, 2010). We confirmed the conclusions by Sauck and Zabik (1992) that the method developed by Taylor and Fleming (1988) is not at all perfect. Moreover, we demonstrated that the inefficiency of the Taylor and Fleming method is not due to field noises; rather it has theoretical reasons.

When the anisotropy paradox - the basis of the Taylor-Fleming interpretation - was taken into account, the efficiency of analogue model results with the increasing sediment thickness became less and less. At the same time, when the anisotropy paradox was ignored, the efficiency increased with the thickness of the overlying sediments.

We concluded from the analogue modelling experiments that either the very long array lengths with the assumption of the anisotropy paradox, or the very short array lengths with ignoring the anisotropy paradox should be applied. An alternative solution could be that much more measurements and their statistical data processing are carried out. 


\subsection{Investigation of multidirectional fissure systems in field}

We elaborated a geoelectrical procedure, namely a combination of profile- and azimuthal measurements, which is able to map multidirectional fissure systems (Szalai et al. 2005, 2006a). One should take into account the following facts:

- An optimal array length should be selected. (If the array length is too long, the fissures can not be separated from each other, if it is too short, the detection depth is not sufficient.)

- After a rainy period, the subsurface is wet, and the fissure effects dominate over the bedrock topography. In this way it is easy to detect the fissures in the bedrock. If the goal is a bedrock topography mapping, it is preferable to carry out the measurements, when the subsurface is dry (Fig. 4).

- If the subsurface is wet, both the Wenner and MAN arrays are good fissure indicators. The Wenner array provides more robust results, while the MAN array is able to detect even the smaller anomalies. The best way is a joint use of the two arrays.

- In case of an optimum array length, the correlation between the fissure directions determined by profiling and azimuthal methods has been found to be acceptable, in spite of the numerous disturbing effects related mainly to the azimuthal measurements. The estimation of the direction is acceptable by using the Schlumberger null array, if the azimuthal measurement site is much closer to one of the fissures than to the neighbouring ones. In case of doubtfulness, the Schlumberger array should also be applied, even if its interpretation is more ambiguous.

The most difficult thing in the interpretation is to correlate the anomalies at the neighbouring profiles, in spite of the fact that the profile measurements were completed by azimuthal measurements to determine the fissure directions. However, carrying out profile measurements by using Wenner- and MAN arrays, and azimuthal measurements by using Schlumberger- and Schlumberger null arrays we were able to map a multidirectional fissure system.

Although there are still many opened questions (first of all in the field of azimuthal measurements), the described procedure is perspective.

\section{Standardized pricking probe (PP) surveying and its use in archaeological prospection}

We have discussed the PP technique and its application to archaeological prospecting (Szalai et al. 2009b, 2011, Fig. 5). In PP measurements a metal rod with a sharp peak is pushed into the soil to a given constant $($ e.g. 20-30 cm) depth. It either penetrates into the soil gently or sticks in. In the first case we assign to the pricking probe location a value of $k=0$, while in the second case a value of $k=1$ is assigned. 


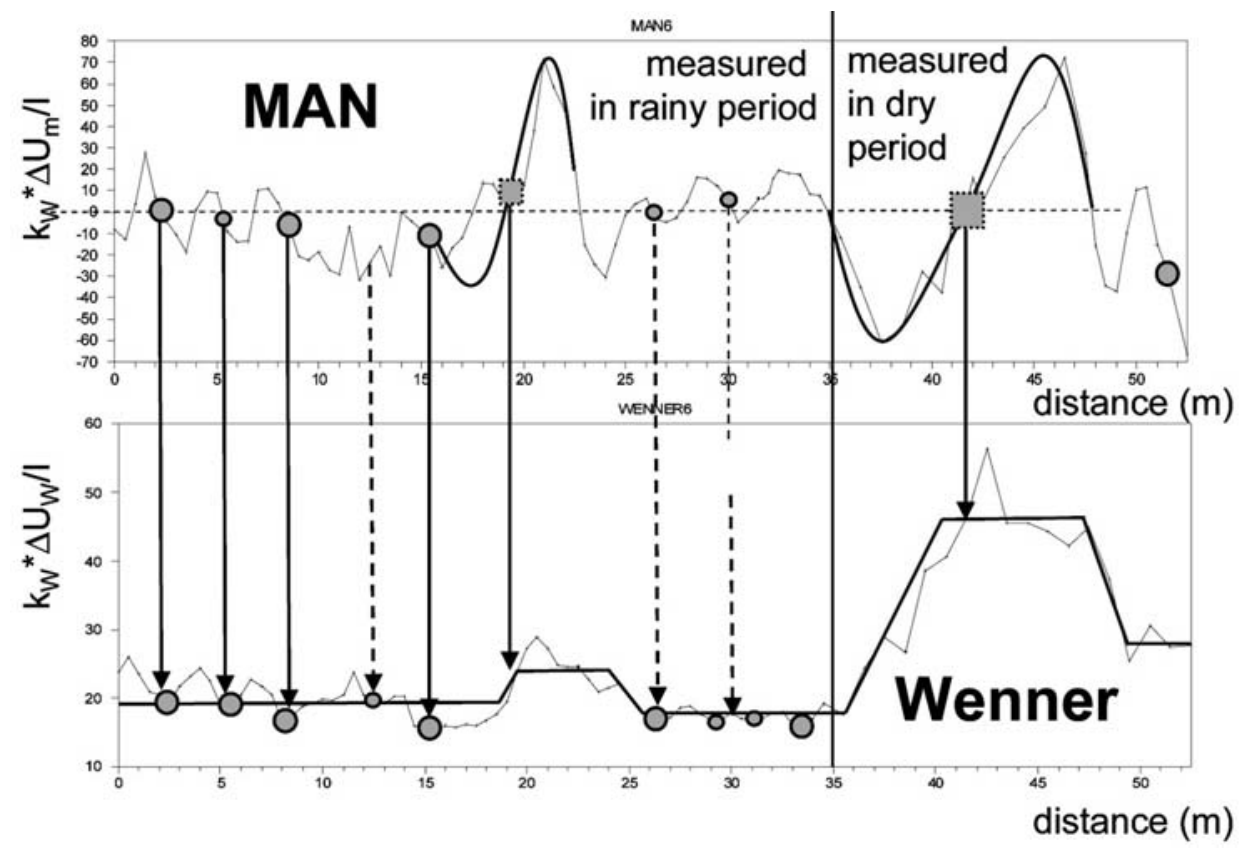

Fig. 4. Profile 6 (measurements started in a rainy, completed in a dry period) with the assumed horsts of bedrock surface (indicated by squares) and fissures (circles). The locations of the anomalies were determined on basis of numerical modelling. Arrows show the corresponding anomalies. The red line shows qualitatively the topographical changes of the bedrock surface. For the MAN array the geometrical coefficient $k$ of the corresponding Wenner array was used
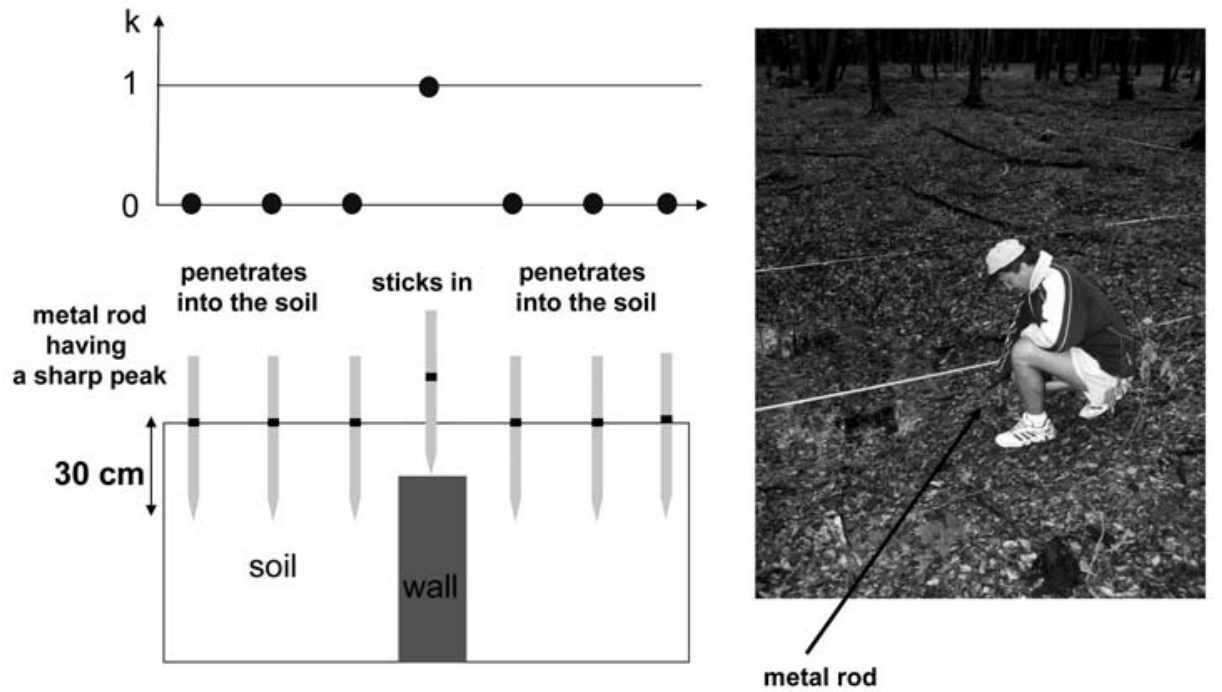

Fig. 5. Scheme of the pricking probe (PP), and a photo about its field application. $k=0$ if the metal rod penetrates into the soil gently, while $k=1$ if it sticks in 

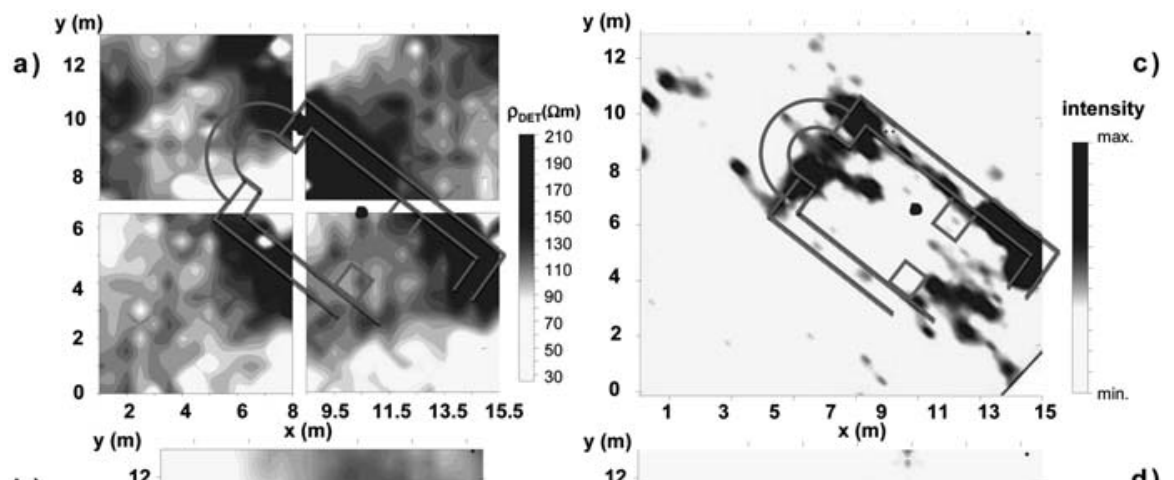

b)
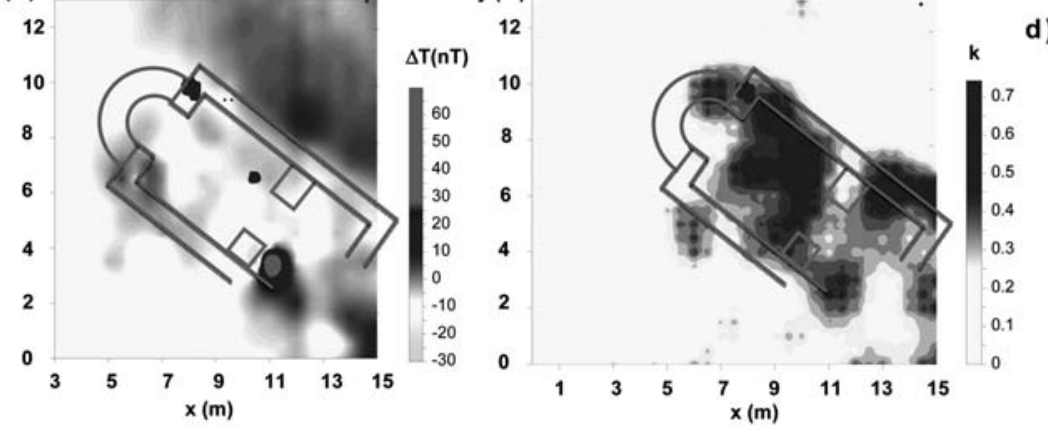

d)

Fig. 6. Results of three standard geophysical methods and of the pricking probe: a) geoelectric method, b) magnetic method, c) georadar, d) pricking-probe

Successful reconnaissance measurements were carried out in case of dense undergrowth, which would have been hardly possible with standard geophysical methods. In the detailed measurements the pricking probe proved to be also competitive (Fig. 6). Only the georadar was able to provide high quality images about the chapel walls, but some details are not seen, or seen less than in PP maps. The imaging power of the $\mathrm{PP}$ technique, especially with a $60 \mathrm{~cm}$ pricking depth, proved to be even superior to the applied geophysical methods.

It is also possible to carry out a gradual deepening, thus a so-called PP-sounding, which makes possible to construct 3D images of the walls (Fig. 7). Among common soil conditions the method can be universally applied, except in presence of significant posterior debris distribution. For a deeper insight it is advisable to remove the uppermost soil layer.

For archaeological reconnaissance measurements, i.e. to find buried archaeological objects a rectangular grid with an interval of $1 \mathrm{~m}$ is recommended, while for a detailed survey a rectangular grid with an interval of $50 \mathrm{~cm}$ is advisable.

We verified that the pricking probe method is very useful in archaeological prospecting because it has several advantages: its field procedure and data processing are simple, cheap and quick; since it does not need electronic instrument, just a metal rode, there are no investment costs, and there is no chance of technical failure; the method can be applied even among the most unfavourable field conditions as bad weather, extreme topography, dense undergrowth, etc.; it is possible to 


\section{Pricking depth}

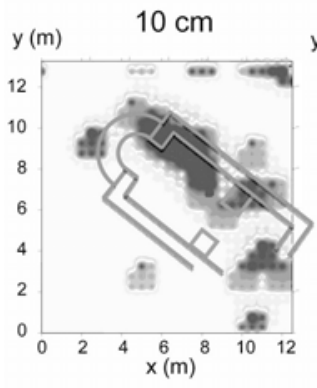

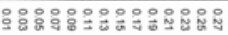
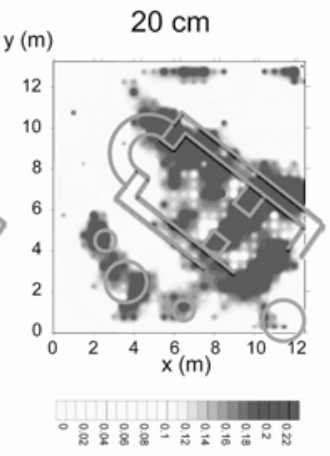
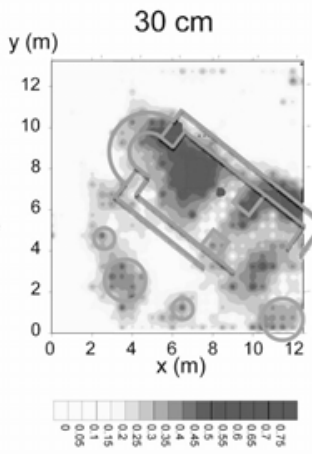
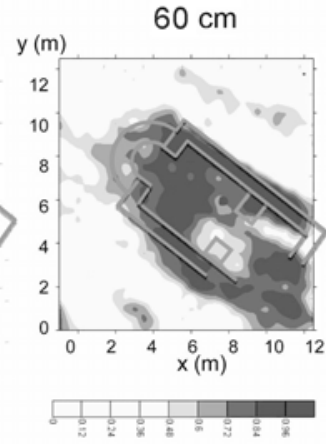

c)

Fig. 7. Sounding with the PP technique with pricking (penetration) depths of 10, 20, 30 and $60 \mathrm{~cm}$

elaborate its sounding variant; it provides complementary information to the geoelectric and georadar maps; it may show some details, remaining hidden by using standard geophysical methods.

We inter-compared altogether four independent methods/techniques over buried object. Most of the archaeological results come from the PP measurements, or they can be seen the best in PP results. On basis of our results we highly recommend to use the PP technique in archaeological prospection, because - at least in our case - it proved to be competitive to standard geophysical methods, considering both its imaging efficiency and economic issues.

On basis of pricking probe (PP) field results in the Homód trench (Bakony Mts) by Szalai et al. (2006b, 2008b), we think that the PP technique is able to provide useful information for the depth distribution of karstic limestone bottom even at the depth range 10-50 m, as well. Although the theoretical basis is not clear, the $\mathrm{PP}$ results are well correlating with the known local structures and also with the traditional geoelectric results.

\section{Conclusions}

In the frame of the OTKA project K49604 we have obtained the following practical results: 1 . In the practice the incorrect positioning of the electrodes for various multielectrode systems are negligible with the exception of a rocky surface, where it is impossible to put the electrodes in the desired positions. The errors can however be kept even in this case within an acceptable range, if the electrodes of the linear arrays are put off-set, at right angles from the measuring line. A five-six times larger off-set has less effect than a certain mis-position along the line, connecting the electrodes. 2. Our tensorial geoelectric measurements provided more detailed and unambiguous anomalies than 2D profile measurements. 3. The 3D ERT technique using the dipole axial array was able to locate in wet environment both the metallic and non-metallic landmines as long as the noise level was about 5\%. 4. We elaborated a geoelectrical procedure which is able to map multidirectional fissure systems 
by combining geoelectrical profiling and geoelectrical azimuthal measurements. The humidity of the fissures affects however the measured results significantly and in a meaningful way. 5. We presented the so-called standardized pricking probe (PP) surveying technique and demonstrated its usefulness in an archaeological study. The PP images proved to be definitely more close to the realistic shape of the buried chapel in the given case than the geoelectric and magnetic measurements, and they also revealed more details about the subsurface than the georadar. The optimum PP parameters: horizontal interval, pricking depth, observable quantity and its way of presentation were optimized through field experiments.

Non-traditional geoelectric arrays and the PP technique have a significant potential in non-destructive investigation of the near-subsurface. Many diverse application are possible.

\section{Acknowledgements}

In frames of the OTKA project K49604 (2005-2008) altogether 68 publications (including reports) were made. 10 SCI papers in English were published, with a cumulative impact factor of 3.725. In English 10 extended abstracts and 6 short abstracts were published. In Hungarian 3 papers and 3 research reports were presented.

\section{References}

Metwaly M, El-Qady G, Matsushima J, Szalai S, Al-Arifi N S N, Taha A 2008: Nonlin. Processes Geophys., 15, 977-986.

Novák A, Szarka L, Varga M, Szalai S, Pap Zs, Károlyi A 2005a: Tensor invariant based electrical potential mapping, and its use in an archeological field study. IAGA WG 1.2 on Electromagnetic Induction in the Earth, Proceedings of the 17th Workshop, http://www.emindia2004.org

Novák A, Varga M, Szalai S, Szarka L 2005b: Tensorial apparent resistivity mapping and archological case study. Paper G 018 EAGE Meeting Madrid

Sauck W A, Zabik S M 1992: SAGEEP'92, 1, 197-222.

Szalai S, Szarka L, Révi G, Varga M 2005: Geoelectric investigation of a multidirectional fissure system in a karstic area. P047 Near Surface 2005, Palermo

Szalai S, Szarka L, Révi G, Varga M 2006a: Geoelectric investigation of a pluridirectional fissure system in a karstic area, Proceedings of the 2nd International Conference on Environmental and Engineering Geophysics (ICEEG), Wuhan, China, Geophysical Solutions for Environment and Engineering, J Wang, Y Xu, J Xia, C Chen eds, Science Press USA Inc., Vol. 1, 287-291.

Szalai S, Veress M, Novák A, Szarka L 2006b: In: Karsztfejlődés 11, M Veress ed., Szombathely, Berzsenyi Dániel Tanárképző Főiskola, 153-170.

Szalai S, Koppán A, Szarka L 2007: Effect of Positional Inaccuracies on Multielectrode Results, 13th European Meeting of Environmental and Engineering Geophysics, Istanbul, P28

Szalai S, Koppán A, Szarka L 2008a: Acta Geod. Geoph. Hung., 43, 33-42.

Szalai S, Veress M, Novák A, Szarka L 2008b: Application of the simplest geophysical method, the pricking probe method to map bedrock topography in a buried karstic area, EAEG-Near-surface, P17, Krakków, Poland

Acta Geod. Geoph. Hung. 46, 2011 
Szalai S, Kósa I, Nagy T, Szarka L 2009a: Effectivity Enhancement of Azimuthal Geoelectric Measurements, Near Surface 2009 - Proceedings of the 15th European Meeting of Environmental and Engineering Geophysics, P25

Szalai S, Lemperger I, Pattantyús Á M, Szarka L 2009b: Pricking Probe as a Complementary Technique in Archeological Prospecting, Near Surface 2009 - Proceedeings of the 15th European Meeting of Environmental and Engineering Geophysics, A03

Szalai S, Kósa I, Nagy T, Szarka L 2010: Acta Geod. Geoph. Hung., 45, 137-147.

Szalai S, Lemperger I, Pattantyús Á M, Szarka L 2011: J. Archaeological Sci., 38, 175-182.

Taylor R W, Fleming A H 1988: Ground Water, 26, 464-474.

Varga M, Novák A, Szarka L 2008: Near Surf. Geophys., 1, 39-48. 